\title{
Cenlestato
}

\section{Usuários da informação como fim em bibliotecas universitárias: uma análise a partir da Teoria Crítica em Adorno e Horkheimer}

\author{
Mariana Rodrigues Gomes de Mello \\ Mestra; Universidade Estadual Paulista; Marília, SP, Brasil; \\ mariana.rg.mello@unesp.br \\ Everton da Silva Camillo \\ Mestre; Universidade Estadual Paulista; Marília, SP, Brasil; \\ everton.camillo@unesp.br \\ João Carlos Gardini Santos \\ Bacharel; Universidade Estadual Paulista (UNESP); Marília, SP, Brasil; \\ joao.carlos@unesp.br \\ Daniel Martínez-Ávila \\ Doutor; Universidad Carlos III de Madrid (UC3M); Getafe, Espanha; \\ dmartine@bib.uc3m.es
}

\begin{abstract}
Resumo: $\mathrm{O}$ estudo objetiva averiguar se a razão emancipatória na Teoria Crítica da Escola de Frankfurt se alinha à expectativa de uso dos serviços e recursos de informação de usuários da informação vinculados a universidades com programas de pós-graduação em Ciência da Informação na região Sudeste do Brasil. Tem como hipótese que os usuários da informação vinculados aos programas constituem o fim da oferta de serviços e recursos de informação pela biblioteca universitária do campus onde cada unidade de informação se localiza. Apresenta relações da Teoria Crítica em Theodor Adorno e Max Horkheimer com as abordagens dos estudos de usuários da informação. Discorre sobre as abordagens tradicional e alternativa dos estudos de usuários e suas relações com a função das bibliotecas universitárias. Os dados da pesquisa foram coletados por meio da aplicação da técnica de questionário. Utilizou-se o método de pesquisa análise de conteúdo. Foram elaborados cinco temas e 15 categorias de análise. Resultou que os temas 'Acesso/organização da biblioteca e do acervo' e 'Colaboradores' foram integralmente considerados alinhados à razão emancipatória. Os temas 'Produtos' e 'Serviços' obtiveram uma categoria alinhada com a razão instrumental cada um, por isso não foram integralmente considerados emancipatórios. A hipótese foi refutada. Conclui-se que tanto os serviços, quanto os recursos de informação são fundamentais para os usuários da informação se emanciparem. Contudo, para que as bibliotecas universitárias consigam atuar socialmente de acordo com a razão emancipatória, elas necessitam focar o usuário da informação como o fim das suas ações, e não como meio para atingi-las.
\end{abstract}


Palavras-chave: Biblioteca universitária. Estudos de usuário. Usuário da informação. Teoria Crítica.

\section{Introdução}

Desde os anos de 1930, os estudos de usuários da informação têm ganhado relevância no cenário científico da Biblioteconomia e da Ciência da Informação (CI). A princípio, nestas pesquisas, objetivava-se conhecer os hábitos de leitura dos usuários das bibliotecas. Isso influenciou, sobretudo, a constituição de marcos teóricos importantes na área da Biblioteconomia nas décadas subsequentes à de 1930. Posteriormente, a própria Ciência da Informação valeuse das construções teórico-metodológicas oriundas da primeira no que se refere a estudar usuários da informação, pois trajetórias empíricas e epistêmicas já haviam sido firmadas anteriormente (RABELLO, 2013; SANTOS et al., 2018).

É prática das unidades de informação, como as bibliotecas, desenvolver estudos de usuários. Esses estudos são, como definiu Figueiredo (1994, p. 7), “[...] investigações que se fazem para saber o que os indivíduos precisam em matéria de informação, ou então, para saber se as necessidades de informação por parte dos usuários de uma biblioteca ou de um centro de informação estão sendo satisfeitas de maneira adequada.”. Por outro lado, Dias e Pires (2004, p. 12) entendem os estudos de usuários como ações para, dentre outros objetivos, "[...] explicar um fenômeno observado de uso ou necessidade expressa de informação; compreender o comportamento dos usuários quanto ao uso da informação (necessidades e não uso da informação) [...]". Desta forma, as bibliotecas conhecem as demandas e necessidades de informação dos seus usuários quando empregam procedimentos metodológicos, a fim de compreender seus comportamentos de busca e de uso da informação.

Os desejos e a avaliação dos usuários em relação ao acervo importam, são fundamentais, a todo tipo de unidade de informação (biblioteca pública, biblioteca especializada, biblioteca universitária, biblioteca escolar, dentre outros). E à biblioteca universitária, que está no cerne desta pesquisa, é fundamental compreender a necessidade de informação e o comportamento informacional dos seus usuários da informação. Ela, que tem funções essenciais 
no Brasil pautadas no tripé ensino, pesquisa e extensão, é percebida por Alcântara e Bernardino (2013, p. 2) como

[...] a instância que possibilita à universidade atender às necessidades de um grupo social ou da sociedade em geral, através da administração do seu patrimônio informacional e do exercício de uma função educativa, ao orientar os usuários na utilização da informação.

Em vista disso, para que a biblioteca universitária sirva à produção do conhecimento, que é um dos seus objetivos, práticas efetivas de gestão organizacional necessitam ser empregadas. Assim, aspectos de tratamento técnico, oferta de produtos e serviços de informação, aplicação de estratégias de marketing, modelos de gestão, segmentação de clientes e demais funções de cunho administrativo são imprescindíveis.

No entanto, salvaguardar a prática da boa gestão organizacional não implica a garantia direta e involuntária da emancipação dos usuários da informação. Em outras palavras, intenta-se dizer que mesmo que unidades de informação disponham de gestão inovadora, não se pode afirmar que seus usuários constituem, aos olhos da Biblioteca, o fim em si das práticas biblioteconômicas.

É por isso que, ao processo de investigação, parte-se do pressuposto de que a biblioteca universitária é um equipamento de informação emancipatório nos campi universitários e ela, no âmbito da sua função social, confere aos usuários da informação o aprendizado de modo livre para a emancipação. Nesse sentido, é seu papel compreender os usuários como o fim, a razão, o porquê das suas ações e não como o meio para atingi-las. Isso, no sentido do pensamento de Horkheimer (2013), significa que a razão objetiva ou emancipatória está ligada à ideia de finalismo ao conhecimento e às ações humanas, concepção oposta à de razão subjetiva ou instrumental, que é subordinada à técnica, ou seja, ao raciocínio preciso e não reflexivo.

Explana-se, portanto, que se objetivou averiguar se a razão emancipatória na Teoria Crítica da Escola de Frankfurt se alinha à expectativa de uso dos serviços e recursos de informação de usuários da informação vinculados às universidades com programas de pós-graduação em Ciência da Informação (PPGCI), na região Sudeste do Brasil. 
A pesquisa é considerada inédita devido aos poucos trabalhos científicos publicados sobre a temática na CI em língua portuguesa. De modo amplo, os trabalhos publicados relacionam aspectos da Teoria Crítica da Escola de Frankfurt à CI, mas não especificamente aos estudos de usuário em bibliotecas universitárias.

O primeiro deles é o de Doyle (2018) que, em seu estudo chamado Ideologia e competência crítica em informação: um olhar para movimentos de biblioteconomia crítica, objetivou relacionar os conceitos de ideologia e competência crítica em informação à Teoria Crítica da sociedade da Escola de Frankfurt para, em seguida, fazer uma aproximação entre a academia e os movimentos sociais que se dedicam a resistir aos efeitos nefastos do sistema capitalista hegemônico. Esses movimentos são o \#Critlib, dos Estados Unidos, e o @RadicalLibs, do Reino Unido. A investigação concluiu que, apesar do mérito de existir, a atuação dos movimentos estudados ainda é tímida e limitada.

Depois, em 2020, Cavalcante, Bufrem e Cortes (2020), no trabalho $A$ Escola de Frankfurt e a Ciência da Informação, objetivaram analisar a influência do pensamento da Escola de Frankfurt na CI. O estudo conclui que os encaminhamentos frankfurtianos erguem-se grandemente como via para se conceber e perceber a informação e a CI em matéria humana, social e críticoreflexiva. Isso possibilitou reafirmar o pertencimento da CI à condição de Ciência Social, muito além de projeções pragmatistas, tecnicistas e positivistas.

Como não foram recuperados trabalhos que frisassem especificamente os usuários da informação e a importância da sua condição-fim em bibliotecas universitárias, esta investigação é justificada por desejar compreender se os serviços e recursos de informação oferecidos nesse tipo de biblioteca vão ao encontro do usuário da informação como o fim das ações da biblioteca universitária. Por isso, tem-se como hipótese de pesquisa que os usuários da informação vinculados aos PPGCI das universidades da região Sudeste do país são o fim da oferta de serviços e recursos de informação pela(s) biblioteca(s) universitária(s) do campus onde cada unidade de informação se localiza.

Para realizar o estudo, delimitou-se como ações específicas apresentar, primeiro, as relações da Teoria Crítica em Theodor Adorno e Max Horkheimer, 
com as abordagens dos estudos de usuários da informação. Depois, discorrer sobre as abordagens tradicional e alternativa dos estudos de usuários e suas relações com a função das bibliotecas universitárias. Essas ações compõem o bojo teórico da investigação, que é considerada exploratória, de natureza mista e descritiva.

\section{Metodologia}

O estudo desenvolvido é considerado exploratório e descritivo, dada a necessidade de compreender a relação entre fenômenos da realidade, e para tanto ter que descrever determinadas condições da própria realidade, tal como compreende Gil (2008). Ainda, a pesquisa é de natureza qualiquantitativa devido não apenas à descrição da realidade, mas à quantificação dos fenômenos averiguados (RICHARDSON, 2012).

Os dados da pesquisa foram coletados por meio da aplicação da técnica de questionário, cujos instrumentos foram enviados por e-mail aos discentes dos programas de pós-graduação em Ciência da Informação da região Sudeste do Brasil. Para a análise dos dados, recorreu-se ao método análise de conteúdo (AC).

A fim de identificar quais são os cursos ativos na região Sudeste na área de Comunicação e Informação e Ciência da Informação, ingressou-se na Plataforma Sucupira e realizou-se o seguinte caminho virtual: Cursos avaliados e reconhecidos > Por área de avaliação > Comunicação e Informação > Ciência da Informação. Identificaram-se, ao final desse procedimento, 24 instituições de ensino que ofertam cursos de mestrado acadêmico, mestrado profissional e doutorado na área de avaliação Comunicação e Informação e na área básica Ciência da Informação. Somadas, essas 24 instituições totalizam 40 cursos de pós-graduação na área básica Ciência da Informação.

Dessas 24 instituições, dez estão localizadas na região Sudeste do país: Fundação Casa de Rui Barbosa (FCRB) - RJ, Universidade de São Paulo (USP) - SP, Universidade Estadual Paulista Júlio de Mesquita Filho, Marília (UNESP) - SP, Universidade Federal de Minas Gerais (UFMG) - MG, Universidade Federal de São Carlos (UFSCAR) - SP, Universidade Federal do Espírito Santo 
(UFES) - ES, Universidade Federal do Estado do Rio de Janeiro (UNIRIO) RJ, Universidade Federal do Rio de Janeiro (UFRJ) - RJ, Universidade Federal Fluminense (UFF) - RJ e Universidade FUMEC (FUMEC) - MG.

Dessas dez instituições, sete possuem programas de pós-graduação em Ciência(s) da Informação (PPGCI) e conferem aos concluintes os títulos de Mestre ou Doutor em Ciência(s) da Informação: USP, UNESP, UFMG, UFSCAR, UFES, UFRJ e UFF. Os discentes convidados a participar desta pesquisa estão vinculados a um destes sete programas. Destacou-se que tanto a USP quanto a UFMG possuem mais de um programa de pós-graduação na área de avaliação Comunicação e Informação e na área básica Ciência da Informação. A USP conta com o programa de pós-graduação em Ciência da Informação e com o programa de pós-graduação em Gestão da Informação. A UFMG possui o programa de pós-graduação em Ciências da Informação e o programa de pós-graduação em Gestão \& Organização do Conhecimento. De ambas as instituições, somente os discentes dos PPGCI foram convidados a responder o questionário.

Para tanto, limitou-se o universo pensando em selecionar apenas os programas em CI, a fim de deixar a pesquisa mais focada em um campo, mostrando maior uniformidade, resultando, assim, traçar um paralelo dos fins das bibliotecas universitárias de um mesmo domínio. Sendo assim, o foco da pesquisa são os alunos regularmente matriculados nos PPGCI da região Sudeste do Brasil, que são frequentadores e usuários das bibliotecas universitárias da Instituição à qual estão vinculados.

É possível identificar que há um ponto de encontro nesta pesquisa ao abranger a temática de estudos de usuários da informação e a Teoria Crítica da Escola de Frankfurt. Ao compreender melhor o usuário da unidade de informação, profissionais da CI podem auxiliá-lo a ser mais autônomo no processo de busca da informação e apropriação da mesma, transformando-a em conhecimento para, então, desenvolver a capacidade crítica de escolha e análise. Devido a isso, esta pesquisa se faz oportuna na medida em que contribui para aprofundar reflexões sobre as dimensões emancipatória e instrumental presentes no âmbito dos usuários da informação em bibliotecas universitárias. 
Sobre a coleta dos dados, optou-se pela aplicação de um questionário eletrônico distribuído por e-mail, com o total de 18 perguntas de múltipla escolha. Ele foi aplicado entre os dias 11 e 30 de junho de 2020. O total de questionários respondidos e retornados foi 66 , que constituíram a amostra da pesquisa. Contudo, destaca-se que nem todos os PPGCI informaram o número total de alunos matriculados em nível de mestrado e doutorado e não ter acesso a este dado incidiu diretamente na caracterização do universo da pesquisa. Apenas a UNESP (191 discentes) e a USP (99 discentes) informaram o número de discentes matriculados. Depois, na amostra, não se obteve retorno de questionários de discentes da UFMG. Assim, a análise é realizada com apenas seis instituições do total inicialmente estabelecido de sete da região Sudeste.

Para realizar a análise dos dados, lançou-se mão da técnica de análise temática do método AC. Os temas atribuídos foram 'Usuário', 'Acesso/organização da biblioteca e do acervo', 'Produtos', 'Serviços' e 'Colaboradores'. Cada tema detém um conjunto de categorias, como visto a seguir:

\section{$\square$ Tema: Usuário}

Categoria 1 - Identificação do respondente

Categoria 2 - Interesse nos resultados da pesquisa

\section{$\square$ Tema: Acesso/organização da biblioteca e do acervo}

Categoria 1 - Horário de funcionamento

Categoria 2 - Localização geográfica da biblioteca

Categoria 3 - Acessibilidade ao prédio

Categoria 4 - Acesso ao acervo

Categoria 5 - Organização das estantes

\section{$\square$ Tema: Produtos}

Categoria 1 - Qualidade, conservação e quantidade de itens no acervo Categoria 2 - Quantidade de computadores

Categoria 3 - Quantidade de cabines individuais e coletivas para estudo 
Mariana Rodrigues Gomes de Mello, Everton da Silva Camillo, João Carlos Gardini Santos, Daniel Martínez-Ávila

Categoria 4 - Mobiliário em geral

$\square$ Tema: Serviços

Categoria 1 - Serviços oferecidos pelas bibliotecas

Categoria 2 - Penalidades

Categoria 3 - Atividades lúdicas

\section{$\square$ Tema: Colaboradores}

\section{Categoria 1 - Colaboradores da biblioteca}

A partir de Bardin (2016, p. 44), entende-se o método AC como “[...] um conjunto de técnicas de análise das comunicações que utiliza procedimentos sistemáticos e objetivos de descrição do conteúdo das mensagens.”. As categorias foram estabelecidas, pois, como entendem Amado, Costa e Crusoé (2014.p. 302-303), dependendo da técnica empregada, a AC

\section{[...] procura 'arrumar' num conjunto de categorias de significação o 'conteúdo manifesto' dos mais diversos tipos e comunicações (protocolo de entrevistas e histórias de vida, documentos de natureza vária, imagens, filmes, propaganda e publicidade).}

Desse modo, com os temas e categorias atribuídos, parte-se para a análise dos dados. E, neste estudo, ela foi realizada mediante a aplicação do seguinte esquema de verificação de condicional:

\section{Se $\left\{\begin{array}{l}\text { Concordo plenamente } U \text { Concordo parcialmente } \geq 50 \% \rightarrow \text { Razão emancipatória } \\ \text { Concordo plenamente } U \text { Concordo parcialmente } \leq 49,9 \% \rightarrow \text { Razão instrumental }\end{array}\right.$}

No questionário, as possibilidades de resposta, que correspondem à uma escala Likert, são: 'Concordo plenamente'; 'Concordo parcialmente'; 'Indiferente'; 'Discordo parcialmente'; 'Discordo plenamente'. Considerando a hipótese da pesquisa, maior ênfase foi dada às respostas registradas nas opções 'Concordo plenamente' e 'Concordo parcialmente' juntas, porque elas revelam se os usuários da informação tendem a experimentar o uso dos serviços e recursos informacionais na(s) biblioteca(s) universitária(s) no contexto da razão emancipatória. Assim, se o valor percentual da união (U) de 'Concordo 
plenamente' com 'Concordo parcialmente' for maior ou igual $(\geq)$ a $50 \%$, classifica-se como razão emancipatória. Caso ocorra o contrário, isto é, o valor percentual de $U$ for menor ou igual $(\leq)$ a $49,9 \%$, indica-se, então, a razão instrumental.

\section{Aspectos da Teoria Crítica em Adorno e Horkheimer para os estudos de usuários}

A Escola de Frankfurt, fundada em meados da década de 1920, foi um movimento político-social e científico de pesquisadores, associada ao Instituto de Pesquisa Social da Universidade de Frankfurt, na Alemanha. No início, o grupo que constituiu a primeira geração de frankfurtianos sofreu fortes influências do marxismo. Walter Benjamin, Theodor Adorno, Max Horkheimer e Herbert Marcuse foram os expoentes da primeira geração e postularam as primeiras reflexões acerca Teoria Crítica que se opõe à teoria clássica, de origem cartesiana. A primeira concepção da Teoria Crítica, assim, foi fruto da reflexão de um grupo de filósofos marxistas, a maioria de origem judaica, que por ocasião da Segunda Guerra Mundial tiveram de se exilar nos Estados Unidos (EUA), transferindo o instituto novamente à Frankfurt somente em 1954 (JAPIASSÚ; MARCONDES, 2005).

A teoria clássica, de raiz cartesiana, criticada pelos frankfurtianos, visa compreender o objeto da ciência tal como ele se manifesta e isto se dá, de modo reducionista, mecanicista, não relacionando as partes com o todo. Tudo isso por meio do olhar acrítico e distante do observador, que passa pelo Iluminismo e tem como auge o positivismo no século XIX. "Os filósofos do Iluminismo atacaram a religião em nome da razão; e ao final o que eles mataram não foi a Igreja, mas a metafísica e o próprio conceito de razão objetiva, a fonte de poder de todos os seus esforços" (HORKHEIMER, 2013, p. 26). Assim, a razão, a partir do século XVIII, foi sendo reduzida à técnica, isto é, à instrumentalidade, desviando-se de um fim maior, ético.

Porém, a Teoria Crítica, diferentemente da clássica, considera a dinâmica das mudanças sociais, a interdisciplinaridade, o papel crítico do pesquisador e o contexto no qual ele está inserido. Ela perpassa, então, por um olhar ético que 
valoriza a coletividade e outro posicionamento do pesquisador, mais reflexivo e atuante. Nessa perspectiva, conforme expõe Cavalcante, Bufrem e Cortês (2020, p. 42):

Evidencia-se, em virtude disso, como projeto teórico promissor, como alça teórica válida para pensar e problematizar os acontecimentos e transformações dos tempos contemporâneos, passando, então, a cativar adeptos(as), a inquietar pensadores(as), a inspirar pesquisadores(as). Constituindo-se, portanto, enquanto eixo promissor para estudos e pesquisas, sobretudo no campo de estudos das Ciências Sociais, reassenta suas discussões e investigações em novas bases, cujos ecos se busca sentir de maneira mais sustentada nos horizontes da Ciência da Informação.

Vale ressaltar que o presente trabalho se concentrou na visão de Adorno e Horkheimer, debruçando-se mais nos aspectos da razão instrumental (ou subjetiva) e da razão objetiva, também denominada de emancipatória, a fim de compreender se as bibliotecas universitárias têm atendido seu papel de veículo na promoção da emancipação dos seus usuários, satisfazendo suas demandas e necessidades.

Em seu livro, a Eclipse da razão (2013), Horkheimer descreve as diferenças entre a razão objetiva e razão subjetiva. Entendemos como razão subjetiva ou instrumental aquela subordinada à técnica, ou seja, ao raciocínio preciso e não reflexivo, que visa aos meios para alcançar um objetivo, não importando se há um fim maior, ético, que contemple o bem comum.

Esta espécie de razão é instintiva, voltada a autopreservação e este é o único fim. É inerente a ela uma dimensão utilitarista, voltada às preferências subjetivas do indivíduo e não um fim que comporte a coletividade. Os filósofos da Escola de Frankfurt entendem essa espécie de razão como a grande expressão do lucro e da propriedade privada que movem o capitalismo. Neste sentido, “[...] a técnica é a essência desse saber, que não visa conceitos e imagens, nem o prazer do discernimento, mas o método, a utilização do trabalho de outros, o capital.” (ADORNO; HORKHEIMER, 1985, p. 18).

Portanto, a ausência de autonomia, reflexão e liberdade criativa nos leva à razão instrumental. "É como se o próprio pensamento tivesse reduzido ao nível do processo industrial, submetido ao programa estrito, em suma, tivesse se tornado uma parte e uma parcela da produção.” (HORKHEIMER, 2013, p. 31). 
Sob este ponto de vista, se consideramos a técnica como um fim em si mesma, até as relações humanas se tornam produtos, fruto da coisificação do espírito. A sensibilidade cessa e o subjetivismo se torna latente e, assim, vamos tratando a nós mesmos e aos outros como mercadorias. Logo, na tecnocracia, somente nos serve o que for útil (ADORNO; HORKHEIMER, 1985). Nas palavras de Adorno e Horkheimer (1985, p. 35):

O preço da dominação não é meramente a alienação dos homens com relação aos objetos dominados; com a coisificação do espírito, as próprias relações dos homens foram enfeitiçadas inclusive as relações de cada indivíduo consigo mesmo.

Entretanto, a razão objetiva ou emancipatória está muito ligada à ideia de finalismo para o conhecimento e as ações humanas (HORKHEIMER, 2013). Fim que ultrapassa a individualidade e os ganhos pessoais, à medida que o bem da coletividade precisa nortear as nossas ações. O outro deve ser enxergado como fim das nossas atitudes e não como um meio para angariarmos ganhos pessoais. Para Adorno (2011), somente a educação de qualidade pode fazer-nos chegar à emancipação. Para tanto, compreendemos que as bibliotecas universitárias têm um papel fundamental na construção de seres autônomos e reflexivos e, portanto, emancipados. É só por meio do exercício da autonomia que poderemos alcançar a razão emancipatória. O princípio da autonomia tem caráter ético e expressa a forma com que cada pessoa vislumbra a possibilidade de direcionar suas ações à coletividade. De acordo com Paulo Freire (2011, p. 58), o “[...] respeito à autonomia e à dignidade de cada um é um imperativo ético e não um favor que podemos ou não conceder uns aos outros.".

Posto isto, um bibliotecário de uma universidade necessita visualizar o usuário da informação como um fim de todas as suas ações; ele não pode ser concebido como o meio da sua permanência no emprego, por exemplo. Compreendemos que algumas dimensões da biblioteca universitária ultrapassam a competência de ação do bibliotecário, haja vista que depende da atuação de outras instâncias que precisam oferecer recursos financeiros para modernizar o acervo, as instalações, adquirir novas tecnologias, entre outras ações.

Contudo, a maioria dos procedimentos realizados na biblioteca depende de atitudes emancipatórias do bibliotecário, a fim de promover a emancipação 


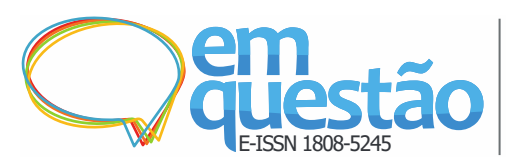

Usuários da informação como fim em bibliotecas universitárias: uma análise a partir da Teoria Crítica em Adorno e Horkheimer

Mariana Rodrigues Gomes de Mello, Everton da Silva Camillo, João Carlos Gardini Santos, Daniel Martínez-Ávila

também do usuário, a partir dos serviços prestados. Todas as ações, segundo Adorno e Horkheimer (1985), que não vislumbrem a coletividade como fim farão parte da razão técnica, por mais reflexivas que possam aparentar. Por isso, elencaram-se, por meio de um questionário, pontos a serem refletidos em conjunto com os alunos dos PPGCI do Sudeste do Brasil, buscando verificar se seus desejos, necessidades e/ou lacunas informacionais (gaps) têm tido respaldo nas bibliotecas das universidades onde estudam. Enfim, se o bem-estar dos usuários, ao buscarem a informação como resposta às suas lacunas informacionais, como coloca Dervin e Nilan (1986), tem sido considerado.

Dervin e Nilan (1986) consideram o usuário como a pessoa capaz de construir a informação, à medida que ele "[...] é visto não como um receptor passivo de informações, mas como um centro ativo." (MORRIS, $1994^{1}$ apud NEVES; CARVALHO, 2000, p. 218). Para isso, operacionam-se as lacunas em questões que são codificadas em categorias. A partir destas, o sujeito constrói a ponte que dá ensejo às respostas e, assim, ao uso da informação. As pontes são elaboradas pela união dos conhecimentos adquiridos recentemente como os já pertinentes à estrutura cognitiva do usuário. O pensamento de Dervin e Nilan (1986) adere perfeitamente ao conceito de razão objetiva ou emancipatória da primeira geração da Escola de Frankfurt e, consequentemente, ao papel do profissional da CI em promover autonomia ao usuário.

Nesta perspectiva, as abordagens de estudos de usuários, sobre as quais discorreremos na seção seguinte, são imprescindíveis para refletirmos a verdadeira importância e alcance que elas têm tido no âmbito das bibliotecas universitárias.

\section{Abordagens tradicional e alternativa dos estudos de usuários frente à função das bibliotecas universitárias}

Inicialmente rotulados como "levantamentos bibliotecários" (library surveys) ou como "enquetes sobre leituras" (reading surveys), os estudos de usuários tiveram início no estrangeiro nos séculos passados (CUNHA; AMARAL; DANTAS, 2015). No Brasil, a expressão "estudo de usuários" começou a ser utilizada em meados do século XX, a partir de uma cisão ocorrida com o 
levantamento bibliotecário, o qual era conhecido por ser caracterizado como uma "[...] coleta sistemática de dados concernentes ao sistema, suas atividades, operações, pessoal, uso e usuários, em um dado momento ou em um período de tempo.” (FIGUEIREDO, 1994, p. 23).

Sendo assim, estudos de usuários podem ser compreendidos, de acordo com Cunha e Cavalcanti (2008, p. 159), como a "[...] pesquisa para saber o que as pessoas necessitam em matéria de informação ou se essas pessoas estão satisfeitas e sendo atendidas adequadamente por seus provedores." e também como "[...] a investigação de como e para que a informação é utilizada pelos usuários, assim como as formas que essas necessidades são expressas e conhecidas.”.

Historicamente, a partir das lições de Cunha, Amaral e Dantas (2015), podemos observar que os estudos de usuários são divididos principalmente em cinco grandes fases: a primeira, com início na década de 1930, surge a partir do interesse em saber o que as pessoas liam e como era essa leitura, além do interesse em saber o motivo pelo qual os indivíduos frequentavam as bibliotecas. Nessa primeira fase, as bibliotecas públicas - já com forte apelo educacional - concentraram os primeiros estudos de usuários, tecnicamente denominados estudos de comunidade, conduzidos por bibliotecários e docentes da Escola de Biblioteconomia da Universidade de Chicago, com o objetivo de analisar a integração dos imigrantes na comunidade norte-americana, através do uso da biblioteca pública.

A segunda fase dos estudos de usuários, que teve início com a Conferência Internacional de Informação Científica da Royal Society, focou nos estudos de uso da informação por cientistas e engenheiros a partir da aplicação principalmente dos questionários e das entrevistas.

A terceira fase, por sua vez, que se inicia a partir de 1965, tem como escopo uma maior abrangência, na medida em que comunidades inteiras de usuários passam a ser estudadas com técnicas mais robustas de observação indireta, a fim de identificar os comportamentos dos usuários. Nesse período também têm início a análise de citações estatísticas de uso das coleções e os 


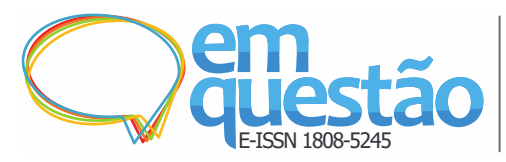

Usuários da informação como fïm em bibliotecas universitárias: uma análise a partir da Teoria Crítica em Adorno e Horkheimer

Mariana Rodrigues Gomes de Mello, Everton da Silva Camillo, João Carlos Gardini Santos, Daniel Martínez-Ávila

estudos sociológicos capazes de identificar os canais de transmissão informais da informação (CUNHA; AMARAL; DANTAS, 2015).

A quarta fase dos estudos de usuários, ocorrida na década de 1970, vivencia um aprofundamento cada vez mais amplo e exploratório dos estudos sociológicos dos usuários da informação. Nesse momento, evidencia-se um novo paradigma a partir do qual os sistemas informacionais deveriam ser ajustados às necessidades informacionais dos usuários e não o contrário.

Por fim, na última e atual fase, que teve início na década de 1990, constatou-se que as unidades informacionais devem priorizar as necessidades de informação dos usuários por meio da oferta de facilidades capazes de atender às demandas, a fim de que eles sejam emancipados, tanto no momento da recuperação, quanto nos da verificação e utilização das informações.

Nessa linha, o desenvolvimento dos estudos de usuários foi pautado em fundamentos e modelos teóricos que propuseram diferentes abordagens. Por um lado, a abordagem tradicional, praticamente carente de modelos teóricos capazes de desenvolver os estudos de usuários, caracteriza-se por uma tradição positivista, com métodos predominantemente quantitativos, capazes de levantar grandes quantidades de dados, mas incapazes de refletir uma nova teoria para a área e capazes de ignorar estudos e pesquisas de outras áreas e que são aptos a convergir com um novo arcabouço teórico para os estudos de usuários.

Nesse sentido, Cunha, Amaral e Dantas (2015, p. 81) explicam que “A abordagem tradicional direcionava o foco para o produto, o serviço ou o sistema de informação, que eram avaliados praticamente desconsiderando aquele a quem se destinava, fosse o usuário individual ou coletivo.”. Dessa forma, exemplos de estudos de usuários com abordagem tradicional, são: a quantidade de empréstimos e de consultas aos sistemas de informação, a quantidade de visitantes diários da biblioteca, entre outros.

Por outro lado, os estudos de usuários a partir da década de 1980 passaram a apresentar uma abordagem alternativa centrada no usuário da informação e fundamentada em métodos e técnicas de coleta de dados mais utilizados nas Ciências Sociais como a observação, as entrevistas, os questionários, os levantamentos (surveys), o grupo focal, entre outros. Sendo 
assim, a abordagem alternativa, centrada no sujeito e que tem como foco o ponto de vista do usuário, remete às questões que envolvem as necessidades, os hábitos e as formas pelas quais os usuários obtêm informação (CUNHA; AMARAL; DANTAS, 2015).

Nesse sentido, a abordagem alternativa dos estudos de usuários apresenta os mais variados modelos teóricos propostos por diversos pesquisadores. Abordaremos a seguir os modelos desenvolvidos cronologicamente por Nicholas J. Belkin (1980), Brenda Dervin (1983), Robert S. Taylor (1986) e Carol C. Kuhlthau (1991).

O modelo teórico proposto por Belkin (1980), conhecido como "anomalous state of knowledge" (ASK) ou estado anômalo do conhecimento, pressupõe que os conhecimentos que uma pessoa tem sobre determinadas tarefas desempenhadas ou sobre determinados problemas enfrentados não são suficientes para resolvê-los. Em razão dessas lacunas, incoerências ou incertezas no conhecimento, é que surgem as necessidades informacionais. Sendo assim, as anomalias no estado do conhecimento das pessoas é que despertam as necessidades de buscas por informações. Belkin (1980) explica que os processos de buscas pelas informações estão fundamentados nessas tarefas ou problemas pessoais. Portanto, para que as tarefas sejam efetivamente concluídas ou os problemas corretamente solucionados, determinadas informações devem ser adquiridas pelas pessoas por meio dos processos de buscas informacionais, os quais são constantemente alterados e adaptados de acordo com os resultados recuperados.

No modelo teórico de Dervin (1983), o sense-making ou construção de sentido, o usuário é compreendido na sua individualidade como ser humano que está constantemente evoluindo e passando por diversas experiências as quais proporcionam construção de significado, mas que, vez ou outra, deve atravessar o chamado vazio cognitivo ou a ausência de informação. Dessa forma, a construção de sentido ocorre quando o sujeito é capaz de observar, interpretar e compreender a realidade, atribuindo-lhe significados.

O modelo teórico de Taylor (1986), o user-values ou value-added ou valor agregado, é uma abordagem alternativa capaz de ser aplicada a qualquer 
ambiente informacional. O modelo propõe que agregar valor é transformar dados sem significado nenhum em uma informação útil. Para que isso ocorra, o modelo apresenta as seguintes premissas teóricas e metodológicas capazes de estudar as pessoas em suas relações com a sociedade e com a informação:

1. A realidade não é completa, ela é permeada de descontinuidades, chamadas lacunas ou gaps.

2. A informação é um produto da observação humana.

3. Toda informação tem um componente subjetivo.

4. A busca e o uso da informação são atividades construtivas.

5. A informação fornece somente uma descrição parcial da realidade. (CUNHA; AMARAL; DANTAS, 2015, p. 102-103)

Por fim, o modelo teórico de Kuhlthau (1991), o information search process (ISP) ou processo de busca da informação, considera o nível de incerteza flutuante das pessoas acerca das informações, dividindo esse processo de busca em seis estágios: 1) a iniciação, no qual há a percepção da necessidade informacional; 2) a seleção, onde há a delimitação do campo ou do tema da pesquisa; 3) a exploração, na qual o material é efetivamente analisado de forma mais ampla e profunda; 4) a formulação, onde é possível estabelecer o foco do problema; 5) a coleta, momento em que há a reunião das informações recuperadas nos sistemas e serviços informacionais; e 6) a apresentação, onde é finalizado e solucionado o problema informacional do sujeito.

Todas essas abordagens alternativas estão centradas, além de outros, no público das bibliotecas universitárias, os quais são formados, de acordo com Otlet (2018), por professores, estudantes, especialistas e pesquisadores, e têm como principal finalidade tentar compreender como ocorre a busca, a apropriação e a interação entre os usuários de sistemas informacionais e a própria informação.

Entretanto, os modelos teóricos utilizados para estudos de usuários, quaisquer que sejam eles, dificilmente conseguem dar conta da complexidade desses estudos. Acrescente-se a essa dificuldade a própria diversidade e pluralidade do público das bibliotecas universitárias, o que acaba resultando em uma maior complexidade no momento da elaboração e aplicação dos estudos de usuários, qualquer que seja o modelo teórico, a técnica ou o método empregado. 
Além disso, Cunha, Amaral e Dantas (2015) destacam que identificar uma necessidade informacional é diferente de satisfazer essa mesma necessidade de informação. Nesse sentido, os autores explicam que apenas além de identificar a necessidade de informação por meio de uma proposta teóricometodológica, é necessário evidenciar quais os caminhos e os significados necessários para a completa satisfação dos usuários de unidades informacionais. Isso significa, nas palavras dos autores, que

[...] se houver a preocupação de identificar as necessidades dos usuários de um serviço de informação, é necessário também que a prestação dos serviços seja voltada para proporcionar a satisfação desses usuários com a oferta de informação proativo e inovadora, capaz de transformar a visão do usuário quanto ao serviço prestado, considerando o valor agregado da informação obtida que satisfez a sua demanda. (CUNHA; AMARAL; DANTAS, 2015, p. 143).

Nesse sentido, considerando a missão das bibliotecas universitárias como responsável por “[...] fornecer infra-estrutura bibliográfica e documental aos cursos, pesquisas e serviços mantidos pela universidade." (FONSECA, 2007, p. 53), é possível identificar claramente a razão de aplicar o questionário proposto em consonância com os objetivos desta pesquisa. Isso porque, a partir dos resultados e discussões, podemos identificar a concretização ou não dos meios e fins propostos pelos modelos teóricos supracitados, uma vez que os próprios usuários das bibliotecas universitárias analisadas é que dizem se estão satisfeitos ou não com os produtos e serviços ofertados nas suas respectivas Instituições, criando, portanto, o elo necessário com a Teoria Crítica da Escola de Frankfurt.

\section{Resultados e discussão}

No tema Usuário, as categorias selecionadas foram 'Identificação do respondente' (categoria 1) e 'Interesse nos resultados da pesquisa' (categoria 2).

Os dados revelam que $45,5 \%$ dos respondentes são discentes matriculados no doutorado. Os outros $54,5 \%$, portanto a maioria, estão no mestrado. Entre doutorandos e mestrandos, a maioria está vinculada à UNESP $(30,3 \%)$ e, em ordem decrescente, à USP (27,3\%), à UFF $(15,2 \%)$ e ao 
IBICT/UFRJ (12,1\%). A UFES e a UFSCAR detêm os mesmos valores, 7,6\% cada.

A maior parte dos discentes está vinculada ao respectivo PPGCI há menos de um ano (34,8\%), seguido dos que estão entre um e dois anos $(33,3 \%)$ e, na sequência, dos que estão entre dois e três anos (21,2\%). Os valores menores correspondem aos discentes que relataram estar vinculados ao seu PPGCI entre três e quatro anos $(7,6 \%)$ e há mais de quatro anos $(3 \%)$, nessa ordem.

Os relatos sobre o tempo de matrícula nos PPGCI sugerem que a maioria dos estudantes está, de fato, matriculada em nível de mestrado, uma vez que, do total dos respondentes, uma parte está matriculada há menos de um ano e a outra, entre um e dois anos. Assim, inferimos que a maioria dos estudantes de mestrado ainda conclui o primeiro ano do curso. A outra parte segue matriculada no segundo ano.

Como uma parte dos discentes está vinculada ao PPGCI entre dois e três anos e entre três e quatro anos, entendemos que eles compõem o grupo de doutorandos, que pode ser dividido em alunos matriculados nos anos iniciais e finais do doutorado. Um pequeno número de pessoas respondeu que está matriculado há mais de quatro anos no PPGCI. Estes, é bem possível, também sejam doutorandos. Não houve registro de pós-doutorandos.

Uma considerável maioria $(78,8 \%)$ relatou frequentar a(s) biblioteca(s) da Instituição. Os outros 21,2\% declararam não a(s) frequentar. E, por fim, e indistintamente da condição de mestrandos e doutorandos, pouco mais da metade dos respondentes $(54,5 \%)$ indicou ter interesse no resultado desta pesquisa. A outra parte $(45,5 \%)$ declarou não se interessar.

O tema seguinte é Acesso/organização da biblioteca e do acervo. Ele tem cinco categorias: 'Horário de funcionamento' (categoria 1), 'Localização geográfica da biblioteca' (categoria 2), 'Acessibilidade ao prédio' (categoria 3), 'Acesso ao acervo' (categoria 4) e 'Organização das estantes' (categoria 5).

Os discentes foram questionados se concordam com o horário de funcionamento da(s) biblioteca(s). A maioria deles $(59,1 \%)$ indicou que concorda totalmente. A parcela de $19,7 \%$ referiu que concorda parcialmente. $\mathrm{Na}$ 
sequência, $12,1 \%$ dos sujeitos da pesquisa se posicionou indiferentemente ao horário de funcionamento da(s) biblioteca(s). Depois, 4,5\% das pessoas discordaram parcialmente e $4,5 \%$ totalmente do horário em que a(s) biblioteca(s) funciona $(\mathrm{m})$.

$\mathrm{Na}$ sequência, os discentes foram indagados se concordam com a localização geográfica da(s) biblioteca(s) no campus. O total de $66,7 \%$ dos discentes concorda plenamente e $22,7 \%$, parcialmente. A porcentagem de posicionamentos indiferentes foi de $6,1 \%$, e os que discordam parcialmente, $4,5 \%$.

Depois, a pergunta feita aos alunos objetivou compreender se eles concordavam com as condições de acessibilidade ao prédio da(s) biblioteca(s). A parcela de $34,8 \%$ dos discentes respondeu que concorda plenamente. Os que concordaram parcialmente correspondem a $37,9 \%$ do total. Houve manifestações de indiferença quanto à questão, contabilizada em 13,6\%. O montante de $6,1 \%$ dos sujeitos da pesquisa discorda parcialmente e 7,6\%, totalmente.

Posteriormente, os estudantes foram indagados se concordam com a acessibilidade ao acervo da(s) biblioteca(s). A monta de $47 \%$ dos participantes indicou que concorda plenamente, ao passo que 37,9\% concordaram parcialmente. Após, 3\% deles são indiferentes à pergunta e 12,1\% discordaram parcialmente.

Por último neste tema, foi perguntado aos estudantes se eles concordam com a forma de organização das estantes na(s) biblioteca(s). Para 50\% dos discentes a concordância é plena, enquanto para $36,4 \%$ é parcial. O número de sujeitos que indicou indiferença à questão foi de 7,6\%. Por outro lado, 6,1\% deles discordaram parcialmente.

Neste tema, a Figura 1 demonstra a porcentagem de usuários da informação que se posicionou com concordância plena e parcial e o percentual dos que adentraram a tag 'Demais respostas'. 


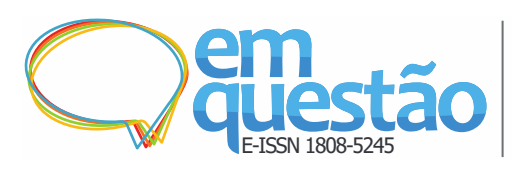

Usuários da informação como fim em bibliotecas universitárias: uma análise a partir da Teoria Crítica em Adorno e Horkheimer

Mariana Rodrigues Gomes de Mello, Everton da Silva Camillo, João Carlos Gardini Santos, Daniel Martínez-Ávila

Figura 1 - Concordâncias no tema 'Acesso/organização da biblioteca e do acervo'.

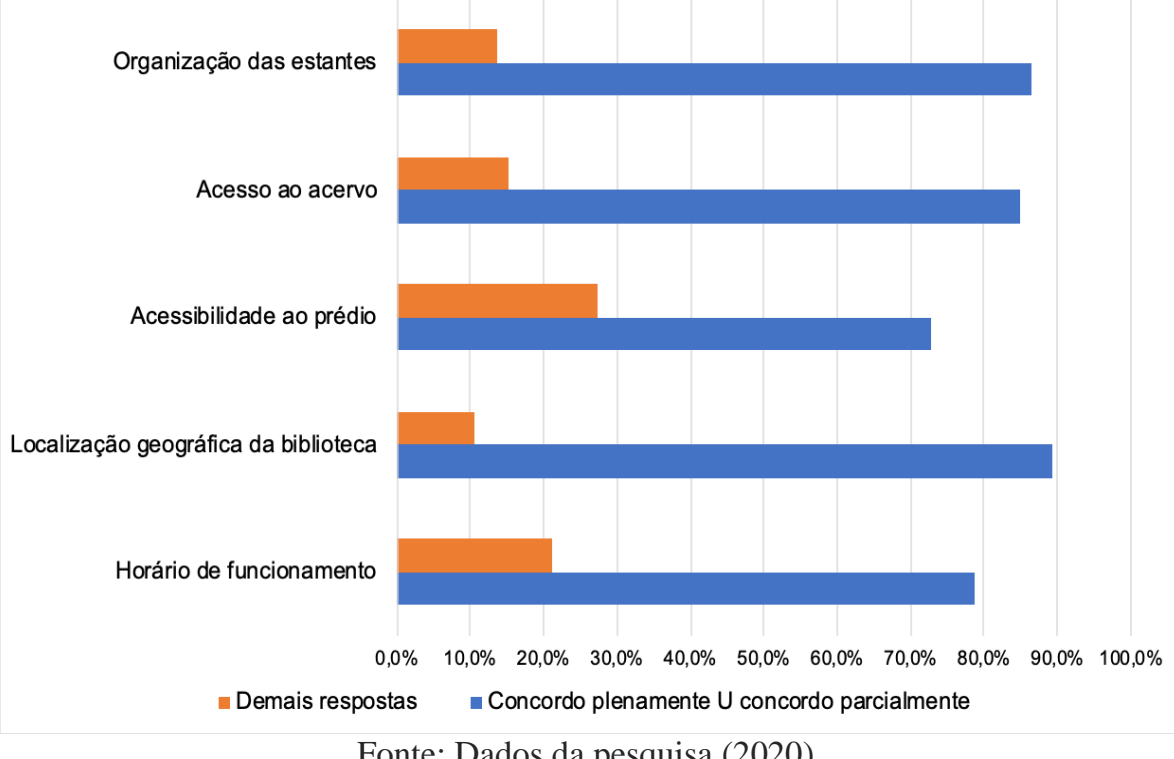

Fonte: Dados da pesquisa (2020).

A Figura 1 evidencia que é significativamente superior a $50 \%$ o percentual de usuários da informação que, juntos, concordaram plena e parcialmente com a experiência que têm em bibliotecas universitárias nas seguintes categorias: 'Horário de funcionamento' (78,8\%), 'Localização geográfica da biblioteca' (89,4\%), 'Acessibilidade ao prédio' (72,7\%), 'Acesso ao acervo' (84,9\%) e 'Organização das estantes' (86,4\%). Desse modo, entendemos que o tema 'Acesso/organização da biblioteca e do acervo' está em consonância com a razão emancipatória.

Com a localização geográfica no campus e o horário de funcionamento ambos adequados, as bibliotecas universitárias podem atender aos usuários da informação com maior efetividade. Tornar o atendimento à coletividade de usuários da informação possível para melhor atendê-los e às suas necessidades informacionais coaduna com a razão emancipatória.

Após, com as acessibilidades ao prédio e ao acervo, sendo ambos adequados, os usuários contam com o respeito às suas diferenças físicas e maior comodidade, inclusão e integração à comunidade e vida universitárias. Até mesmo a forma como as estantes são organizadas parece estar em consonância com a satisfação dos usuários da informação. Estas são situações em que também se destaca o finalismo das ações humanas. 
Na Figura 1, a descrição 'Demais respostas' demonstra que 21,1\% dos alunos não tiveram suas expectativas atingidas quanto à categoria 'Horário de funcionamento'. Na sequência, 10,6\% deles foram indiferentes e discordaram parcial e plenamente quanto à 'Localização geográfica da biblioteca'. O mesmo ocorreu com as categorias 'Acessibilidade ao prédio' (27,3\%), 'Acesso ao acervo' $(15,1 \%)$ e 'Organização das estantes' $(13,6 \%)$.

O próximo tema é Produtos, que tem quatro categorias: 'Qualidade, conservação e quantidade de itens no acervo' (categoria 1), 'Quantidade de computadores' (categoria 2), 'Quantidade de cabines individuais e coletivas para estudo' (categoria 3) e 'Mobiliário em geral' (categoria 4).

Os estudantes foram questionados se concordam com a qualidade, conservação e quantidade de itens no acervo. Assim, 24,2\% dos alunos concordaram plenamente e 48,5\% deles, parcialmente. Os que indicaram indiferença representam 7,6\% do total. Depois, 18,2\% deles discordaram parcialmente e $1,5 \%$, totalmente.

A próxima indagação foi sobre a quantidade de computadores na biblioteca para uso. Para 22,7\% dos participantes a concordância foi plena. Para $25,8 \%$ ela foi parcial. Discentes indiferentes a esta categoria foram $16,7 \%$. Os que discordaram parcialmente correspondem à parcela de $15,2 \%$ e os que o fizeram totalmente, $19,3 \%$.

No que se refere à quantidade de cabines individuais e coletivas para estudo, a parcela de alunos que concordou plenamente é $19,7 \%$ e a dos que concordaram parcialmente é $33,3 \%$. Os que são indiferentes a esta categoria representam 15,2\%. Na sequência, 16,7\% discordaram parcialmente e 15,2\%, totalmente.

Também foi perguntado aos discentes sobre o mobiliário em geral. E para 31,8\% deles a concordância foi plena. Para 37,9\% foi parcial. Os que foram indiferentes a esta categoria refletem $10,6 \%$ do total. Os que discordaram parcialmente figuram $18,2 \%$ e os que discordaram totalmente, $1,5 \%$.

A Figura 2, a seguir, se refere ao tema 'Produtos', que demonstra a porcentagem de usuários que se posicionaram com concordância plena e parcial. Também expõe o percentual daqueles na tag 'Demais respostas'. 
Figura 2 - Concordâncias no tema 'Produtos'.

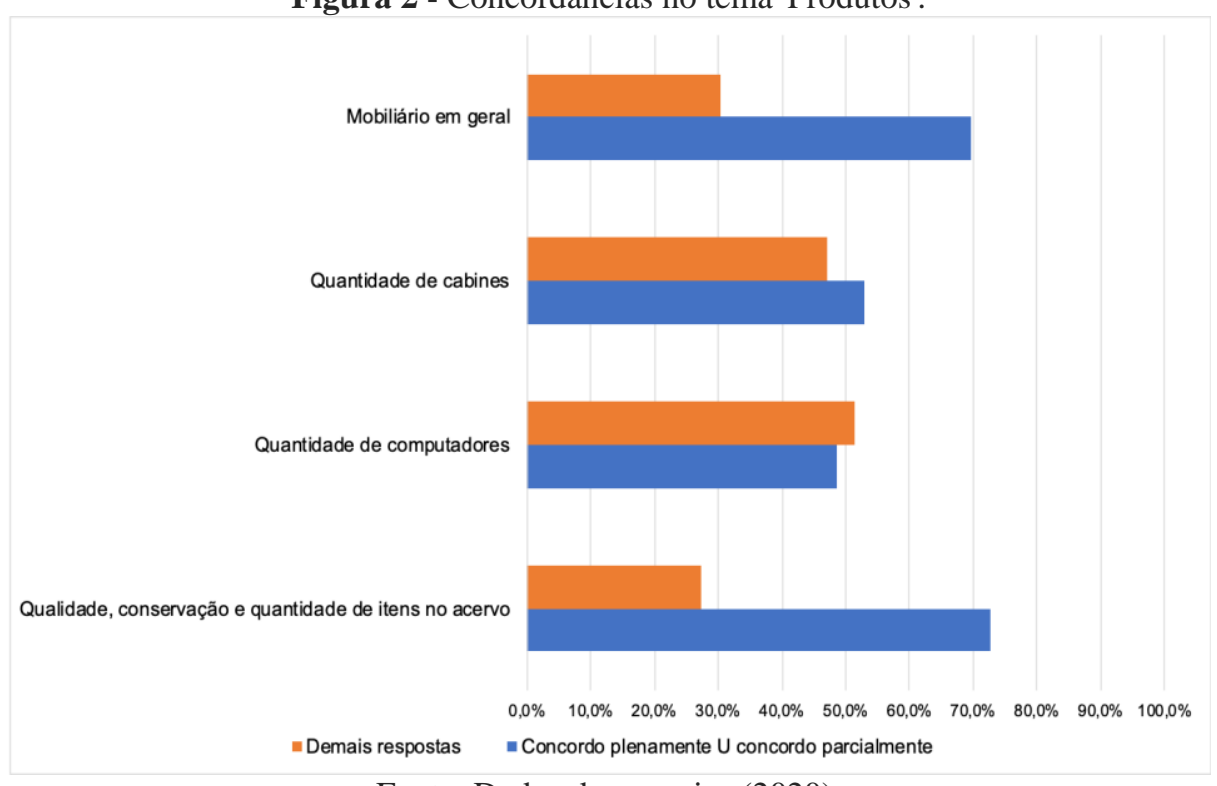

Fonte: Dados da pesquisa (2020).

A partir da leitura da Figura 2, compreendemos que os usuários da informação que concordaram plena e parcialmente representam, juntos, 72,7\% em 'Qualidade, conservação e quantidade de itens no acervo', 69,7\% em 'Mobiliário em geral', 53\% em 'Quantidade de cabines individuais e coletivas para estudo' e 48,5\% em 'Quantidade de computadores'. Contudo, como a categoria 2 tem valor menor que 49,9\%, e por isso se alinha à razão instrumental, não foi possível afirmar que o tema 'Produtos' esteja integralmente em consonância com a razão emancipatória.

As concordâncias nas categorias 'Qualidade, conservação e quantidade de itens no acervo' e o 'Mobiliário em geral' são as que mais se destacam no tema 'Produtos'. Isso viabiliza a compreensão de que os usuários da informação, próximo dos $70 \%$ em cada categoria, sentem-se satisfeitos. Ainda que a categoria 'Quantidade de cabines individuais e coletivas para estudo' não evidencie significativa satisfação dos usuários da informação, ela pertence ao conjunto das que, no âmbito deste tema, vão em direção da razão emancipatória, que são a 'Qualidade, conservação e quantidade de itens no acervo', a 'Quantidade de cabines individuais e coletivas para estudo' e a 'Mobiliário em geral'. 
$\mathrm{Na}$ biblioteca universitária, o usuário da informação depende de infraestrutura elementar que o apoie nas suas atividades de ensino, pesquisa e extensão. Logo, os recursos físicos, humanos, tecnológicos e de informação são imprescindíveis para que os estudantes utilizem serviços e recursos de informação orientados à emancipação. No plano dos recursos de informação, são destacados os itens do acervo; no dos recursos físicos, as cabines para estudo e o mobiliário; e no dos recursos tecnológicos, os computadores para uso na(s) biblioteca(s).

Na tag 'Demais respostas', a categoria 'Quantidade de computador' corresponde a $51,5 \%$. Isso significa que mais da metade dos discentes indicaram estar indiferentes e discordaram parcial e totalmente nesta categoria. Posteriormente, $47 \%$ correspondem à categoria 'Quantidade de cabines individuais e coletivas para estudo', 30,3\% à 'Mobiliário em geral' e 27,3\% à 'Qualidade, conservação e quantidade de itens no acervo'.

Na sequência, há o tema Serviços, com três categorias: 'Serviços oferecidos pelas bibliotecas' (categoria 1), 'Penalidades' (categoria 2) e 'Atividades lúdicas' (categoria 3).

Os sujeitos da pesquisa foram indagados se concordam com os serviços oferecidos pelas bibliotecas. Mais da metade deles (53\%) referiu concordar plenamente e 30,3\%, parcialmente. No que se refere aos sujeitos que se posicionaram indiferentemente a esta categoria, seu percentual é de $12,1 \%$. Alunos que discordaram parcialmente representam $4,5 \%$.

Em seguida, a questão se referiu às penalidades aplicadas pela(s) biblioteca(s). Assim, 75,8\% dos discentes concordaram plenamente que é recorrente a biblioteca da universidade aplicar penalidades. E 4,5\% deles concordaram parcialmente. Tiveram postura indiferente a esta categoria $16,7 \%$ dos sujeitos da pesquisa. Depois, 1,5\% discordaram parcialmente e 1,5\%, totalmente.

Por último, os estudantes foram questionados se concordam com o oferecimento de atividades lúdicas pela(s) biblioteca(s). Exatos 25,8\% dos alunos indicaram que concordam plenamente e $4,5 \%$, parcialmente. A parcela 
dos que registraram 'Indiferente' como resposta é de 39,4\%. Outros 4,5 discordaram parcialmente e $25,8 \%$, totalmente.

Na sequência, a Figura 3, sobre 'Serviços', expõe o percentual de usuários que se posicionaram com concordância plena e parcial, e, de outro lado, os que, juntos, se posicionaram indiferentemente e discordaram, contabilizados sob a tag 'Demais respostas'.

Figura 3 - Concordâncias no tema 'Serviços'.

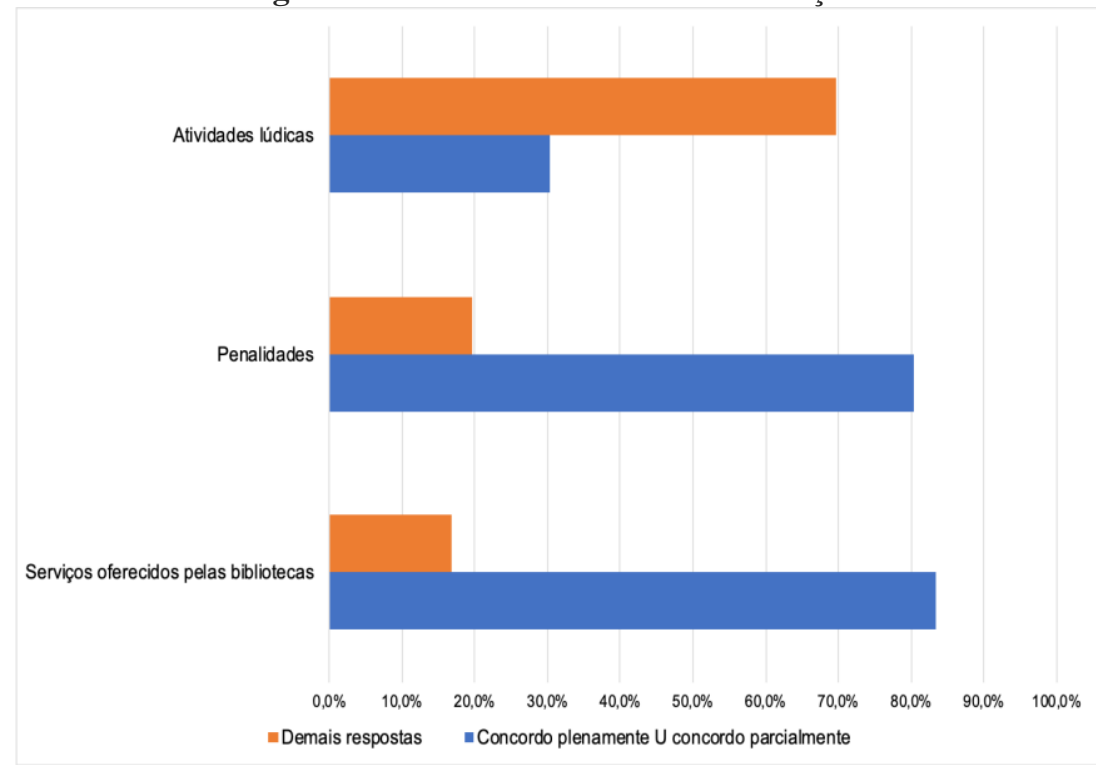

Fonte: Dados da pesquisa (2020).

Depreendemos da leitura da Figura 3 que 83,3\% dos sujeitos da pesquisa concordaram plena e parcialmente com os serviços que a(s) biblioteca(s) universitária(s) oferece(m). No que tange às penalidades aplicadas por elas, $80,3 \%$ deles concordaram que a biblioteca os penaliza com multas e suspensões para empréstimo. Além disso, 69,7\% deles discordaram e são indiferentes às atividades lúdicas (quebra-cabeça, jogos de tabuleiro etc.) desenvolvidas na(s) biblioteca(s) do(s) campus, mas seu percentual de concordâncias plena e parcial corresponde a $30,3 \%$, valor menor que o limite de $49,9 \%$. Portanto, a categoria 'Atividades lúdicas' vai em direção à razão instrumental e devido a isso o tema 'Serviços' não está integralmente voltado à razão emancipatória.

Pudemos considerar que os usuários da informação se sentem satisfeitos em relação aos serviços que a(s) biblioteca(s) universitária(s) oferece(m). No entanto, sugerimos como interpretação que eles se incomodam com as multas e 
Mariana Rodrigues Gomes de Mello, Everton da Silva Camillo, João Carlos Gardini Santos, Daniel Martínez-Ávila

penalizações aplicadas por ela(s). Na biblioteca universitária, os usuários da informação recorrem aos produtos e serviços de informação a fim de que tenham a sua necessidade de informação saciada parcial e momentaneamente. Nesse sentido, eles rumam à emancipação. Entretanto, a aplicação de penalizações relacionadas ao atraso de itens do acervo, dentre outros eventos ligados propriamente aos recursos de informação, desestabiliza a constante da emancipação dos estudantes. As penalizações devem ser amplamente discutidas no âmbito da gestão da unidade de informação e acordos que não firam a razão emancipatória no uso das bibliotecas podem ser mais bem aceitos pela comunidade universitária.

O tema Colaboradores é o último em análise. Ele tem apenas uma categoria, denominada 'Colaboradores da biblioteca' (categoria 1).

Foi perguntado aos discentes se eles concordam que os colaboradores $\mathrm{da}(\mathrm{s})$ biblioteca(s) da universidade os auxiliam quando necessitam de orientação. E metade (50\%) concordou plenamente. Outros 30,3\%, parcialmente. Depois, $12,1 \%$ se posicionaram indiferentemente a esta categoria e outros $7,6 \%$ discordaram parcialmente.

A Figura 4, sobre 'Colaboradores', expõe os dados sobre os discentes que se posicionaram em concordância plena e parcial e os que se posicionaram indiferentemente e discordaram neste tema e categoria.

Figura 4 - Concordâncias no tema 'Colaboradores'.

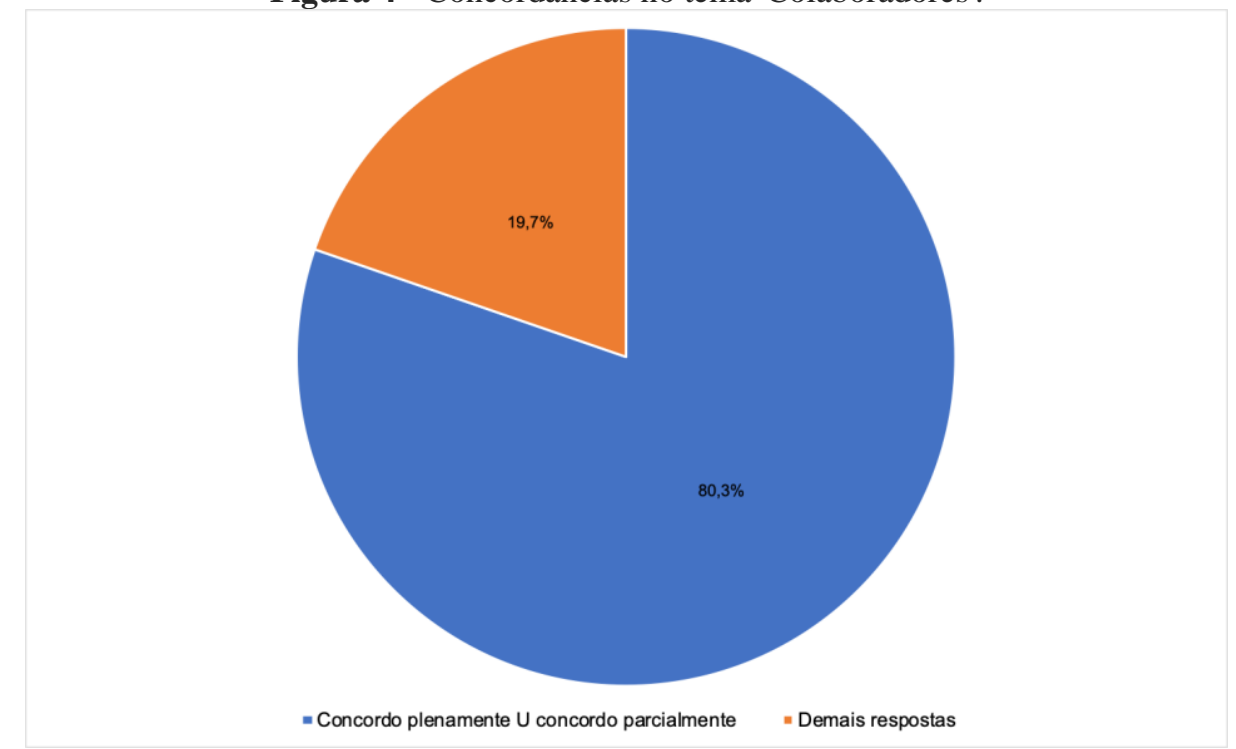

Fonte: Dados da pesquisa (2020). 
Ao que os dados da pesquisa indicam, uma significativa parcela $(80,3 \%)$ dos usuários da informação se sente satisfeita no que tange a contar com a ajuda, quando requisitada, dos colaboradores da(s) biblioteca(s) universitária(s). Isso evidencia que os recursos humanos de grande parte das unidades de informação caracterizadas nesta pesquisa adotam comportamento e postura profissionais ligados à razão emancipatória. Em decorrência disso, o tema 'Colaboradores' e sua única categoria vão, portanto, no sentido da emancipação dos usuários da informação.

Os estudantes que indicaram 'Indiferente' e que concordaram parcial ou totalmente nesta categoria representam $19,7 \%$ do total.

\section{Considerações finais}

A pesquisa objetivou averiguar se a razão emancipatória na Teoria Crítica da Escola de Frankfurt se alinha à expectativa de uso dos serviços e recursos de informação de usuários da informação, vinculados a universidades com PPGCI na região Sudeste do Brasil.

Para realizar o estudo, importou apresentar relações da Teoria Crítica em Theodor Adorno e Max Horkheimer com as abordagens dos estudos de usuários da informação. Assim, compreendemos que o usuário não pode ser concebido como um mero receptor passivo das informações, mas tem de ser observado como um sujeito ativo, capaz de agregar conhecimentos. Tal constatação se alinha perfeitamente à concepção de razão emancipatória da Escola de Frankfurt, podendo subsidiar teoricamente o papel de auxiliar na promoção da autonomia dos alunos que a biblioteca universitária precisa ter.

Depois, foi fundamental discorrer sobre as abordagens tradicional e alternativa dos estudos de usuários e suas relações com a função das bibliotecas universitárias. Essa seção possibilitou o entendimento de que as bibliotecas universitárias têm toda sua administração e organização focada no bom atendimento aos usuários. Dessa forma, a abordagem tradicional dos estudos de usuário não se coaduna com o que deve ser a atual biblioteca universitária, uma vez que nessa abordagem o foco é todo direcionado para o produto, serviço ou sistema de informação. Por outro lado, a abordagem alternativa está voltada para 
o próprio usuário da informação e mantém relação direta com a razão emancipatória proposta pela Teoria Crítica da Escola de Frankfurt, ao contrário da abordagem tradicional que está mais atrelada à razão instrumental.

Inicialmente, a hipótese deste estudo era de que os usuários da informação vinculados aos PPGCI das universidades da região Sudeste do Brasil são o fim da oferta de serviços e recursos de informação pela(s) biblioteca(s) universitária(s) de cada Instituição. Assim, em virtude da análise dos dados ter ocorrido de forma segmentada por temas e categorias, foi possível afirmar que nem todos os temas se enquadram na razão emancipatória, devido ao resultado relacionado a algumas categorias. $\mathrm{Na}$ análise, algumas delas possibilitaram que fosse evidenciado, contudo, que ações biblioteconômicas específicas das bibliotecas das universidades com PPGCI no Sudeste vão em direção à razão instrumental. E, deste modo, a hipótese da pesquisa foi refutada.

Na pesquisa, o tema 'Acesso/organização da biblioteca e do acervo' se alinha integralmente à razão emancipatória. Nele, os usuários da informação são o fim da oferta de serviços e produtos de informação, assim como no tema 'Colaboradores'.

Na sequência, o tema 'Produtos' não está integralmente em consonância com a razão emancipatória, pois uma das suas categorias se vincula à razão instrumental. E o mesmo ocorre com o tema 'Serviços', que também dispõe de uma categoria de análise nessa razão.

Por fim, constatou-se que os serviços e recursos de informação são fundamentais para os usuários da informação se emancipar. E todos os recursos físicos, humanos, tecnológicos e de informação importam nesse processo. Contudo, para que as bibliotecas universitárias consigam atuar socialmente de acordo com a razão emancipatória elas necessitam focar o usuário da informação como o fim das suas ações e não como meio para atingi-las, situação que nos conduz a perspectivá-lo unicamente sob a abordagem alternativa dos estudos de usuários. 


\section{Referências}

ADORNO, T. W. Educação e emancipação. 2.ed. São Paulo: Paz e Terra, 2011.

ADORNO, T. W.; HORKHEIMER, M. Dialética do esclarecimento. Rio de Janeiro: Zahar, 1985.

ALCÂNTARA, F. L. C.; BERNARDINO, M. C. R. O papel da biblioteca universitária como mediadora no processo de ensino-aprendizagem nas bibliotecas universitárias na cidade de Juazeiro do Norte - CE. Múltiplos Olhares em Ciência da Informação, Belo Horizonte, v. 3, n. 2, maio 2013. Disponível em: https://periodicos.ufmg.br/index.php/moci/article/view/17474. Acesso em: 23 set. 2020.

AMADO, J.; COSTA, A. P.; CRUSOÉ, N. A técnica de Análise de Conteúdo. In: AMADO, J. (Coord.). Manual de investigação qualitativa em educação. 2. ed. Coimbra: Imprensa da Universidade de Coimbra, 2014. p. 301-351.

BARDIN, L. Análise de conteúdo. São Paulo: Edições 70, 2016.

BELKIN, N. J. Anomalous states of knowledge as a basis for information retrieval. The Canadian Journal of Information Science, Toronto, v. 5, p. 133-143, 1980.

CAVAlCANTE, A. V. B.; BUFREM, L. S.; CÔRTES, G. R. A Escola de Frankfurt e a Ciência da Informação. Logeion: filosofia da informação, Rio de Janeiro, v. 6, n. 2, p. 40-60, mar./ago. 2020. Disponível em:

http://revista.ibict.br/fiinf/article/view/5101/4540. Acesso em: 23 set. 2020.

CUNHA, M. B.; AMARAL, S. A.; DANTAS, E. B. Manual de estudo de usuários da informação. São Paulo: Atlas, 2015.

CUNHA, M. B.; CAVALCANTI, C. R. O. Dicionário de Biblioteconomia e Arquivologia. Brasília, DF: Briquet de Lemos / Livros, 2008.

DIAS, M. M. K.; PIRES, D. Usos e usuários da informação. São Carlos, SP: UFSCAR, 2004.

DERVIN, B. An overview of sense-making research: concepts, methods and results to date. In: International Communication Association Annual Meeting, 19., 1983, Dallas, Texas, USA. Anais [...]. Dallas: International Communication Association, 1983. p. 1-72.

DERVIN, B.; NILAN, M. Information needs and uses. Annual review of information science and technology, Nova York, v. 21, p. 3-33, 1986.

DOYLE, A. Ideologia e competência crítica em informação: um olhar para movimentos de biblioteconomia crítica. Revista Folha de Rosto, Cariri, v. 4, n. 
1, p. 25-33, jan./jun. 2018. Disponível em:

https://periodicos.ufca.edu.br/ojs/index.php/folhaderosto/article/view/274/248.

Acesso em: 23 set. 2020.

FIGUEIREDO, N. M. Estudos de uso e usuários da informação. Brasília, DF: IBICT, 1994.

FONSECA, E. N. Introdução à Biblioteconomia. 2. ed. Brasília, DF: Briquet de Lemos / Livros, 2007.

FREIRE, P. Pedagogia da autonomia: saberes necessários à prática educativa. São Paulo: Paz e Terra, 2011.

GIL, A. C. Métodos e técnicas de pesquisa social. 6. ed. São Paulo: Atlas, 2008.

HORKHEIMER, M. Eclipse da razão. São Paulo: Centauro, 2013.

JAPIASSÚ, H.; MARCONDES, D. Pós-Modernidade. In: Dicionário básico de filosofia. Rio de Janeiro: Zahar, 2005.

KUHLTHAU, C. C. Inside the search process: information seeking from the user's perspective. Journal of the American Society Information Science, Baltimore, v. 42, n. 5, p. 361-371, 1991.

MORRIS, R. C. T. Toward a user-centered information service. Journal of the American Society for Information Science, Baltimore, v. 45, n. 1, p. 20-30, 1994.

NEVES, J. T. R.; CARVALHO, A. C. M. Análise das necessidades e usos de informação em empresas incubadas de biotecnologia de Minas Gerais.

Perspectivas em Ciência da Informação, Belo Horizonte, v. 5, n. 2, p. 217230, jul./dez. 2000. Disponível em:

http://portaldeperiodicos.eci.ufmg.br/index.php/pci/article/view/10/323. Acesso em: 23 set. 2020.

OTLET, P. Tratado de documentação: o livro sobre o livro teoria e prática. Brasília, DF: Briquet de Lemos / Livros, 2018.

RABELLO, R. Leituras sobre usuário e uso de informação na ciência da informação. Perspectivas em Ciência da Informação, Belo Horizonte, v. 18, n. 4, p. 152-184. out./dez. 2013. Disponível em:

http://portaldeperiodicos.eci.ufmg.br/index.php/pci/article/view/1735/1214. Acesso em: 23 set. 2020.

RICHARDSON, R. J. Pesquisa social: métodos e técnicas. 3. ed. São Paulo: Atlas, 2012. 
Mariana Rodrigues Gomes de Mello, Everton da Silva Camillo, João Carlos Gardini Santos, Daniel Martínez-Ávila

SANTOS, R. R. et al. Estudo de uso: análise da circulação do acervo no contexto universitário. Revista Conhecimento em Ação, Rio de Janeiro, v. 2, n. 1, jan./jun. 2018. Disponível em: https://revistas.ufrj.br/index.php/rca/article/view/16882/11126. Acesso em: 23 set. 2020 .

TAYLOR, R. S. Value-added processes in information system. Norwood: Ablex, 1986.

\title{
Information users as the goal of university libraries: an analysis based on Adorno and Horkheimer's Critical Theory
}

\begin{abstract}
This paper aims to investigate whether the emancipatory reason in the Frankfurt School's critical theory is aligned with the expectations of the users of information services and resources in universities of the Southeast region of Brazil offering graduate programs in Information Science. The research hypothesis is that information users in these Programs constitute the main goal of the information services and resources of these university libraries. The study presents the relationship between critical theory in Theodor Adorno and Max Horkheimer with the approaches of the information user studies. It discusses the traditional and alternative approaches on user studies and their relationship with the function of university libraries. The survey data were collected through the application of a questionnaire. The Content Analysis research method was applied by establishing five topics and fifteen categories. The research findings reveal that the topics 'Access/organization of the library and the collection' and 'Collaborators' were aligned with the emancipatory reason. The topics 'Products' and 'Services' correspond both to the categories aligned with the instrumental reason. Thus, the hypothesis was refuted. The paper concludes that information services and resources are essential for information users to become emancipated. However, for university libraries to be able to act socially according to the emancipatory reason, it is required approaching the information users as the very end of university libraries' actions and not just as the mean of them.
\end{abstract}

Keywords: University library. User studies. Information users. Critical theory.

Recebido: 23/09/2020

Aceito: 05/03/2021 
Mariana Rodrigues Gomes de Mello, Everton da Silva Camillo, João Carlos Gardini Santos, Daniel Martínez-Ávila

\section{Declaração de autoria}

Concepção e elaboração do estudo: Mariana Rodrigues Gomes de Mello, Everton da Silva Camillo, João Carlos Gardini Santos, Daniel Martínez-Ávila

Coleta de dados: Mariana Rodrigues Gomes de Mello, Everton da Silva Camillo, João Carlos Gardini Santos, Daniel Martínez-Ávila

Análise e interpretação de dados: Mariana Rodrigues Gomes de Mello, Everton da Silva Camillo, João Carlos Gardini Santos, Daniel Martínez-Ávila

Redação: Mariana Rodrigues Gomes de Mello, Everton da Silva Camillo, João Carlos Gardini Santos, Daniel Martínez-Ávila

Revisão crítica do manuscrito: Mariana Rodrigues Gomes de Mello, Everton da Silva Camillo, João Carlos Gardini Santos, Daniel Martínez-Ávila

\section{Como citar}

MELLO, Mariana Rodrigues Gomes de; CAMILLO, Everton da Silva; SANTOS, João Carlos Gardini; MARTÍNEZ-ÁVILA, Daniel. Usuários da informação como fim em bibliotecas universitárias: uma análise a partir da Teoria Crítica em Adorno e Horkheimer. Em Questão, Porto Alegre, v. 27, n. 3, p. 141-171, 2021. Doi: http://dx.doi.org/10.19132/1808-5245273.141-171

\footnotetext{
${ }^{1}$ MORRIS, R. C. T. Toward a user-centered information service. Journal of the American Society for Information Science, v. 45, n. 1, p. 20-30, 1994.
} 